the moving pictures on a screen at about the same time that Lumière was showing his in Paris. He gave his first public exhibition in the lecture room of the Finsbury Technical College, where he had formerly been a student. Hatton Garden is associated with Michael Faraday in that he had business relations with Johnson and Matthey of No. 79. Edward Barnard, of the firm occupying No. 54 (the old Court House), was father of Sarah Barnard who married Faraday. Miss Alice Faraday married Fred Barnard, grandson of Ed. Barnard, and a well-known illustrator of Dickens. For a century the district has been famous for skilled craftsmen, makers of optical apparatus, clocks and also of jewellery, etc., including pearls and diamonds. It is now the world centre for the diamond trade.

\section{Russian Eclipse Measurements on the Ionosphere}

WE have received some preliminary results from Prof. W. Kessenich, of Tomsk, U.S.S.R., of the measurements made there on the ionosphere during the total eclipse of June 19, 1936, at the suggestion of Prof. Bonch-Bruevich, and as part of the general scientific eclipse programme of the Russian Academy of Sciences. The main radio work was directed towards the solution of the problem of the source of the ionization of the $F_{2}$-layer, since earlier eclipses have indicated that the $E$ and $F_{1}$ layers are mainly ionized by ultra-violet light. The daily variations in the critical frequencies of the ordinary $\left(f_{o}\right)$ and extraordinary $\left(f_{x}\right)$ rays for the $F_{2}$ layer were measured, by the pulse method, from June 16 until June 24 : in addition, qualitative measurements were made, at a constant frequency, on the absorption changes during the eclipse. The receiving apparatus was in the same room as the transmitter, and included two cathode ray oscillographs, one for visual observation and the other for recording: this arrangement eriabled critical frequencies to be measured in one or two minutes with an accuracy of 1 or 2 per cent. The interpretation of the results is unfortunately somewhat limited by the fact that a world-wide magnetic disturbance set in at about three hours before optical totality: this seems in no way connected with the eclipse.

THE observations were made near Tomsk, at a place about $5 \mathrm{~km}$. north of the central line of the optical eclipse, and $4^{\circ}$ south of the centre of the corpuscular eclipse (the corpuscular track, for three corpuscular speeds, 800,1600 and $3200 \mathrm{~km}$./sec., had previously been calculated by A. Michailov). The average critical frequencies observed during the six days were much larger than those for preceding years observed elsewhere; this may be attributed to the influence of the sunspot cycle. The observations show a marked decrease in ionization of the $F_{2}$ layer during the optical eclipse, suggesting that ultra. violet light is an important part of the source of the ionization; the time of recombination seems to be of the order five minutes, agreeing with the quick appearance and disappearance of absorption at sunrise and sunset observed on preceding and following days. The occurrence of minimum ionization somewhat before totality is regarded as clearly demon. strating the temperature effects suggested by Apple. ton and Naismith. As regards corpuscular influence, the results are interpreted as indicating that solar particles with velocities of the order 1000-2000 $\mathrm{km}$./sec. play an important part in ionizing the $F_{3}$ layer, while corpuscles of larger speed are without influence. The stronger eclipse effects observed on June 19, as compared with those found during preceding eclipses, can be ascribed partly to the summer conditions and partly to the increased solar activity in 1936. Taking into account this increased solar activity, and the high level of critical frequencies, which decreased markedly $2 \frac{1}{2}$ hours before totality, Prof. Kessenich and his collaborators Baerwald, Bulatov and Denisov are inclined to regard the corpuscular ionizing influences on the $F_{2}$ layer as established.

\section{Sale of Newtoniana}

As a result of the sale of the Newton Papers, and other articles of interest in connexion with Sir Isaac Newton, by Messrs. Sotheby and Co. on July 13-14, two gifts of scientific importance have now been made possible, and are worthy of record. That portion of the Papers which deal with Newton's work as warden, and afterwards master, of the Royal Mint, is bound in three folio volumes and contains 529 pieces. These were sold for $£ 1,400$ to $\mathrm{Mr}$. Gabriel Wells who placed them at the disposal of Lord Wakefield at cost, on the understanding that they would be presented to the nation. Lord Wakefield has presented them to the Royal Mint, where they will be available for inspection. The very valuable and unique collection of Newtoniana already in the possession of the Royal Society has been enhanced by a gift from Sir Robert Hadfield which he purchased at the same sale. The gift comprises the following letters : four from Edmund Halley to Newton: four from Edmund Halley to Thomas Molyneux; two from Fontenelle to Newton ; one from Philip Naudé to Newton ; and one from Brook Taylor to Newton. A portrait of Sir Isaac Newton, painted in 1702 by Sir Godfrey Kneller (the most famous of the Newton portraits), has been purchased by the Trustees of the National Portrait Gallery (with a contribution of half from the National Art-Collections Fund) from Messrs. Rosenbach, of New York. The portrait was actually sold at the same sale for $£ 800$, but through the generosity of Dr. Philip Rosenbach, was re-sold to the Trustees of the Gallery at cost price. Among the many other items of interest in connexion with Newton disposed of at the sale were the following : nine letters to Newton from Edmund Halley, containing the history of the publication of the "Principia" ( $£ 310$ ); a note-book in Newton's own handwriting, giving an interesting and amusing list of expenses, and, at the other end, various problems in geometry and conic sections $(£ 180)$; an autographed draft of about 1,000 words of a very important statement on the invention of the calculus (£210). 